\title{
O RISCO COMO ORGANIZADOR DAS EXPERIÊNCIAS DE ATLETAS DE VAQUEJADA DO SERTÃO PERNAMBUCANO
}

\author{
RISK AS ORGANIZER OF RODEO ATHLETES' EXPERIENCE IN \\ PERNAMBUCO'S BACKLANDS
}

\author{
EL RIESGO COMO ORGANIZADOR DE LAS EXPERIENCIAS DE ATLETAS DE \\ RODEO DEL INTERIOR PERNAMBUCANO
}

José Murilo Gomes de Lima*, Roberta de Sousa Mélo**

Palavras chave:

Corpo.

Cultura.

Risco.

Keywords:

Body.

Culture.

Risk.

\begin{abstract}
Resumo: A vaquejada é tida como uma manifestação tradicional do Nordeste brasileiro. Seu processo de reconhecimento como atividade profissional tem sido marcado por novas regras e exigências e, dentre essas, o controle de riscos que historicamente têm sido associados a essa prática. Considerando tais mudanças, o estudo investigou os modos pelos quais a percepção do risco tem mobilizado o cotidiano de um grupo de vaqueiros. Utilizamos uma abordagem qualitativa e realizamos uma observação participante em conjunto com entrevistas semiestruturadas. Participaram deste estudo 19 vaqueiros. A análise dos dados foi guiada pelas premissas da antropologia interpretativa. Os participantes reconhecem a gestão dos riscos como uma responsabilidade individual. Identificam nas novas dinâmicas da vaquejada o estímulo à reflexividade tido como fundamental para a mitigação das ameaças. Através de saberes e de atitudes tecnicamente orientadas, racionalizam os perigos de sua rotina de vaqueiro cultivando disposições corporais e emocionais que assegurem sua permanência nesse universo.
\end{abstract}

Abstract: Rodeos are a traditional manifestation in Northeastern Brazil. Its recognition as a professional activity has been marked by new rules and demands and, among them, control risks historically associated to that practice. Considering such changes, this research investigated how risk perception has mobilized everyday life of a group of rodeo professionals. We used qualitative approach and held active observation along with semi-structured interviews. Subjects were 19 rodeo professionals; data analysis was guided based on interpretive anthropology. Subjects acknowledge risk management as individual responsibility. They find stimuli at the new rodeo dynamics for reflection seen as fundamental to mitigate threats. Through knowledge and technically oriented actions, they rationalize the dangers of their rodeo routine by cultivating bodily as well as emotional dispositions that guarantee their permanence in that universe.

Palabras clave:

Cuerpo.

Cultura.

Riesgo.
Resumen: El rodeo es considerado una manifestación tradicional del nordeste brasileño. Su proceso de reconocimiento como actividad profesional ha sido marcado por nuevas reglas y exigencias y, entre estas, el control de riesgos que históricamente han sido asociados a esa práctica. Considerando tales cambios, el estudio investigó los modos en que la percepción del riesgo ha movilizado el cotidiano de un grupo de vaqueros. Utilizamos una perspectiva cualitativa y realizamos una observación participante en conjunto con entrevistas semiestructuradas. Participaron del estudio 19 vaqueros. El análisis de los datos fue orientado por las premisas de la antropología interpretativa. Los participantes reconocen la gestión de los riesgos como una responsabilidad individual. Identifican en las nuevas dinámicas del rodeo el estímulo a la reflexión, considerado como fundamental para la mitigación de las amenazas. A través de saberes y de actitudes técnicamente orientadas, racionalizan los peligros de su rutina de vaquero cultivando disposiciones corporales y emocionales que aseguren su permanencia en ese universo.
* Autarquia Educacional de Serra Talhada. Serra Talhada, PE. Brasil. E-mail: murilogomeslima@yahoo. com.br

** Universidade Federal do Vale do São Francisco. Petrolina, PE. Brasil. E-mail: roberta.smelo@univasf.edu.br

Recebido em: 19/09/2018 Aprovado em: 07/12/2018

DOI: https://doi.org/10.22456/1982-8918.86800 (c) (i) (8) Licence 


\section{INTRODUÇÃO}

A vaquejada é uma atividade recreativa/competitiva tida como manifestação tradicional e popular do Nordeste brasileiro, sendo uma das práticas mais relevantes e presentes nas regiões estudadas. Consegue atrair um grande público em seus eventos, além de gerar empregos e movimentar o setor financeiro dos municípios nordestinos. Nos últimos anos modernizou-se e hoje é uma prática profissional que vem enfrentando um "processo de esportivização", através de regras oficiais estabelecidas pela Associação Brasileira de Vaquejada (ABVAQ), órgão responsável por sua regulamentação.

Os novos códigos elaborados em torno da atividade têm se tornado objeto de discussão em esferas que vão além do universo da vaquejada. Nos últimos anos ocorreram vários debates políticos envolvendo o tema. No início de Outubro de 2016, o Supremo Tribunal Federal (STF) realizou o julgamento final do projeto de lei estadual do Ceará, ํㅜ 15.299/2013², que visa regulamentar a vaquejada como prática desportiva e cultural e estabelecer as regras para sua realização, bem como fixar os critérios para a competição, obrigando os organizadores a adotarem medidas de segurança para os vaqueiros, o público e os animais.

No mesmo ano do encaminhamento deste projeto ao órgão competente, também foi declarada uma ação direta de inconstitucionalidade, a fim de suspender a lei estadual, apontando o caráter cruel e abjeto da prática. O STF analisou e reconheceu sua inconstitucionalidade sob 0 argumento principal da violência da prática que expõe os animais a maus-tratos e agressão, impondo sofrimento à espécie e ferindo, deste modo, princípios constitucionais de preservação do meio ambiente.

Vale ressaltar que os meios midiáticos e o cenário político têm se configurado como importantes esferas de produção e visibilidade de narrativas e discursos que vêm orientando parte significativa das resoluções em torno da vaquejada.

Em suma, várias alterações têm sido realizadas na busca pelo reconhecimento da vaquejada como desporto e atividade cultural, de modo a diminuir os danos físicos tanto para os vaqueiros como para os animais envolvidos. $O$ uso da tecnologia nas competições oficiais está contribuindo para amenizar os riscos presentes nessa atividade. Além disso, tem havido exigências para assegurar a integridade física dos competidores, como a criação e utilização de equipamentos de segurança, tais como o capacete e luvas apropriadas.

Os esforços pela sua modernização têm se dado como forma de dissociá-la de atributos como barbárie e selvageria. $O$ apelo à prevenção e minimização dos riscos envolvidos passou a integrar as práticas habituais envolvidas na vaquejada e, portanto, a rotina do vaqueiro. Desse modo, ainda que continue sendo reconhecida como uma prática fortemente atrelada à violência, a vaquejada passou a ser mediada por novos códigos de civilidade.

Ainda no que diz respeito aos processos de profissionalização envolvendo a atividade, a ABVAQ elaborou, em 2014, o primeiro regulamento unificado da modalidade, com base em outros já existentes, estabelecendo, assim, diretrizes e normas para a organização e realização dos eventos em todo o Brasil. Ao mesmo tempo, destacaram-se as questões de proteção ambiental e segurança em geral. Posteriormente, outras alterações foram incorporadas ao documento, contribuindo para a legalização da vaquejada e fortalecendo a luta por seu reconhecimento como esporte. 
Não obstante as transformações que têm marcado a prática da vaquejada, alguns aspectos permanecem no imaginário cultural como marca da figura do vaqueiro: atributos como bravura e valentia continuam vinculados às suas construções identitárias, no que seu envolvimento com os riscos envolvidos na prática segue tendo um sentido fundamental. Mesmo diante do referido processo de profissionalização, os riscos da prática não foram totalmente excluídos: ao contrário disso, permanecem incorporados à dinâmica da vaquejada, sendo agora entendidos como elementos a serem negociados pelos sujeitos envolvidos. Esses, por sua vez, o fazem através de saberes específicos, de atitudes tecnicamente orientadas e de disposições corporais e psicológicas intencionalmente trabalhadas em função de seu desempenho, conforme buscaremos mostrar ao longo deste trabalho. Assim, a presença dos perigos não se constitui precisamente como uma novidade na rotina do ser vaqueiro, mas seu entendimento e os modos de lidar com ela se realizam, agora, sob novos códigos.

Amodernização da vaquejada inaugura uma mediaçãotécnica dos riscos. Nesse sentido, ainda que não possam ser plenamente controlados, são passíveis de serem administrados por meio do planejamento e da racionalização. Logo, isso também traz questões cruciais aos processos subjetivos dos vaqueiros, dado que o próprio indivíduo passa a responsabilizarse pela administração adequada dos perigos a que se vê exposto: 0 autocontrole se torna 0 elemento-chave nesse cenário, no que se inclui a gestão do corpo e do próprio comportamento.

Foi a partir dos processos de conscientização realizados a partir de suas tentativas de adequar-se às novas regras da vaquejada que pudemos perceber a presença do risco como elemento que se faz presente de forma significativa em seu cotidiano, impondo-lhes uma racionalização constante de sua rotina e de seus hábitos. Essa dinâmica nos remete à identificação de Elias e Dunning (1992) daquilo que seria a gênese do processo moderno de "desportivização" que os autores associam diretamente ao projeto de civilização e às transformações estruturais e comportamentais da modernidade. Nesse cenário marcado por novas regras e códigos e, sobretudo, pelo enaltecimento da capacidade racional, o autocontrole se torna elemento-chave, assim como a contenção das emoções e dos impulsos que agora só poderiam ser liberados em ocasiões adequadas e permitidas pelas novas normas sociais. Foi fundamental, portanto, a difusão de um processo de subjetivação pelo qual o indivíduo passou a se ver, ele próprio, como um domínio a ser constantemente monitorado. Até certo ponto, essa dinâmica civilizatória, pautada num ideal de modernização, coincide com a do cenário aqui estudado, dado que ele traz como fundo o valor moral do controle de tudo aquilo que emerge a despeito de uma intencionalidade orientada pelos padrões civilizatórios. Assim, a racionalização dos riscos intentada pelos vaqueiros entrevistados parece nos falar, antes de tudo, de uma ética de si.

Trataremos de uma configuração em que o critério da segurança técnica aparece como correlato a uma ideia de responsabilidade individual, convergência também percebida por Mélo (2012) quando se refere ao valor dos processos subjetivos que marcam a contemporaneidade. Do mesmo modo, ao nos falar da prevenção de riscos como questão crucial com que os indivíduos contemporâneos precisam lidar em seu cotidiano, a obra de Beck (1992) nos inspira a pensar sobre um trabalho de reflexividade atrelado à nossa percepção das ameaças que nos rodeiam. Diante disso, buscamos entender o risco como aquilo que, em parte, é uma experiência social, considerando que o seu sentido, a compreensão que se tem dele e os modos como é administrado variam de acordo com o cenário social e suas referências. 
No caso dos entrevistados, a disposição a encarar os riscos foi frequentemente justificada em razão de sua paixão pela vaquejada e por uma busca por prazer. Nesses termos, verifica-se uma concepção positiva do risco, tal como assinalada por Moura, Ferreira e Soares (2016) num estudo sobre discursos produzidos em torno dos esportes de aventura. Por esse aspecto, ele é pensado como algo procurado pelos indivíduos com a intenção de experimentarem sensações agradáveis. Os mesmos autores também identificam a alusão a uma dinâmica de racionalização dos riscos, pela qual a tensão criada por modalidades como os esportes de aventura seria algo negociado de forma consciente pelo praticante (MOURA; FERREIRA; SOARES, 2016, p.9). Por esse mesmo caminho, entendemos que os indivíduos definem suas vivências do risco a partir de lógicas próprias.

Através de nosso estudo verificamos que a exposição a determinados perigos se configurou como um dos principais alvos da gestão desses sujeitos, vindo a ser, portanto, um aspecto crucial para a afirmação de sua capacidade reflexiva e de autocontrole, o que se afina aos processos percebidos pelos autores já citados. Diante dessas considerações, o objetivo deste estudo foi compreender os modos pelos quais a percepção do risco se reflete na gestão de si e na organização das experiências cotidianas dos vaqueiros.

\section{PROCEDIMENTOS METODOLÓGICOS: EU VOU PRA VAQUEJADA}

Uma vez que este estudo se situa no campo das relações sociais e da subjetividade humana, concentrando-se nas ações e vivências cotidianas dos vaqueiros, adotamos uma metodologia qualitativa, buscando a compreensão dos significados individuais e socioculturais envolvidos em suas experiências.

As técnicas de investigação e coleta das informações consistiram na observação participante, na aplicação de entrevistas semiestruturadas e no uso de recursos da Etnografia mais especificamente, o diário de campo, como estratégias complementares e intercambiáveis. Deste modo, desenvolvemos um roteiro de coleta, registro e sistematização das informações.

As observações de campo aconteceram no período de junho de 2017 a março de 2018 em cinco cidades do Sertão Pernambucano. Ao todo foram observados sete eventos que ocorreram nas cidades de Petrolina, Tabira, Serra Talhada, Flores e Exu.

A etapa da coleta de dados teve início após aprovação dada pelo Comitê de Ética e Deontologia em Estudos e Pesquisas da Universidade Federal do Vale do São Francisco.

Os participantes foram abordados nos intervalos dos eventos ou em situações propícias à apresentação dos objetivos da pesquisa e realização das entrevistas. Participaram deste estudo 19 vaqueiros, sendo seis da categoria profissional e 13 das categorias aspirante e amador. Todos do sexo masculino, com idade entre 19 a 49 anos.

As entrevistas foram gravadas e arquivadas em um aplicativo de celular e, posteriormente, transcritas e analisadas.

De modo a garantir seu anonimato e, assim, preservar a imagem dos entrevistados, optamos por identificá-los através do nome da cidade de origem ou da cidade onde foi entrevistado, ao que também acrescentamos sua idade. Por exemplo: Vaqueiro Serra Talhada 35. Nesses termos, a referência ao município não necessariamente o caracterizará como seu habitante. 
A análise dos dados foi guiada pelas premissas metodológicas da antropologia interpretativa de Geertz (2008), em que se observa o esforço pelo entendimento das perspectivas e das experiências de grupos e indivíduos a partir do contexto em que se encontram. De tal modo, realizamos uma leitura com vistas à compreensão e interpretação do nosso material empírico, orientada pela lógica da "descrição densa" proposta pelo autor, pela qual o pesquisador apreende e apresenta uma multiplicidade de estruturas complexas (GEERTZ, 2008 p. 7). No mais, cabe frisar que o material foi também analisado à luz do referencial teórico utilizado.

\section{PROFISSÃO PERIGO: AS SAGAS DO SUJEITO VAQUEIRO}

Conforme viemos sugerindo até aqui, a submissão aos riscos, embora comumente associada a uma atitude irracional, apareceu como parte constituinte dos trabalhos de racionalização e conscientização nas vivências descritas pelos desportistas vaqueiros. A reflexão sobre os perigos envolvidos se constitui, a partir das suas próprias falas, como um mecanismo pelo qual se distinguem as formas mais recentes da vaquejada, sobretudo porque Ihes exige uma necessidade contínua de preparação e de cuidados:

[O vaqueiro] tem que primar pelo preparo físico. Eu já vi muitos vaqueiros top mesmo; eles primam pelo preparo físico deles. [...] Eles têm que fazer isso também com os animais, pra poder ter um rendimento melhor nas competições. Então tudo isso tem que ter regras, coisa que antes não tinha. Era uma prática cultural que a gente fazia de todo jeito e estava ótimo... regras de preparo físico regulamente, [também para] evitar problemas (Vaqueiro Petrolina 43).

As competições exigem muito mais do preparo físico hoje do que antigamente. [...] Então a gente que deve se preparar e se preocupar com a forma física, tanto da gente, como eu falei, como dos animais. [...] Tem aquele preparo de fazer alongamento antes de entrar diretamente na pista, faz com o cavalo também, fazendo aqueles exercícios devagar para que o cavalo aqueça antes de entrar na pista de competição, como se a gente já estivesse na pista correndo com o boi. [...] Então esse preparo tem que ser feito antes. 0 vaqueiro, se puder, tem que fazer alongamentos, [...] tá em academia treinando pra tá em forma e até mesmo pra tá se defendendo pra, na hora de uma queda, saber fazer um rolamento. Eu fiz judô por muito tempo pra aprender a cair (Vaqueiro Petrolina 43).

Tal como verificado num estudo desenvolvido por Sousa e Brollo (2011), um primeiro risco apontado como frequente na rotina dos vaqueiros diz respeito à possibilidade de lesões:

Como em qualquer outro tipo de esporte de contato, no futebol, por exemplo, há o risco. [...] Mas, assim, a gente tem que ter bastante cuidado, prestar bastante atenção. Apesar de ser um esporte rápido, tem que ter um raciocínio rápido também (Vaqueiro Bezerros 35).

Como qualquer outra atividade esportiva, pode trazer danos, como no futebol, que você pode quebrar a perna, ou em qualquer outro esporte, e a lesão é uma coisa natural do esforço físico, seja do humano ou do animal. Então a gente vê jogadores de futebol que recebem milhões e milhões por ano e têm um acompanhamento laboratorial diário e [ainda assim] eles se machucam, eles sofrem lesões, porque todo esporte de alto nível leva o corpo a um limite. Então da mesma forma que acontece a lesão no jogador de futebol, pode acontecer na vaquejada, e por isso que hoje tá acontecendo uma formação de cadeia de profissionais, para tratar isso (Vaqueiro Brejo Santo 33). 
Outras experiências foram narradas, revelando como o risco de acidentes se constitui como elemento marcante nas suas vivências corporais e nas memórias de sua trajetória como vaqueiro:

Eu bati com a cabeça na parede e eu estava sem capacete, levei nove, dez pontos na cabeça. Quase morro. Se eu estivesse de capacete não tinha me cortado, com certeza não (Vaqueiro Petrolina 39).

Eu já cheguei a cair, e infelizmente 0 animal chegou até a morrer neste acidente. Eu levei um corte, mas graças a Deus estou aqui e estou forte para contar a história (Vaqueiro Exu 30).

Já tive um músculo rompido, no bíceps, mas graças a Deus fiz um processo de fisioterapia e hoje já estou competido novamente (Vaqueiro Serra talhada 35).

A gente sabe que ali, apesar de tá se apresentando, fazendo o que gosta, existem riscos enormes. Pode se acidentar, quebrar um braço, uma perna, até mesmo vir a óbito, porque você está mexendo com o bruto. Eu tenho a articulação do antebraço [que eu acredito que] já está comprometida, por causa de um boi que eu puxei errado. Pegou na posição errada e eu acredito que rompeu um ligamento. 0 joelho esquerdo também tem um ligamento cruzado posterior também rompido de uma queda de cavalo. Já soube de uns vaqueiros que perderam a vida. Tem uns seis meses que um rapaz [...] não estava usando o capacete. Ele foi caindo e bateu a cabeça em uma estaca da cerca e morreu na hora (Vaqueiro Santa Terezinha 49).

Pelo exposto, a ressignificação dos riscos se faz, sobretudo, ao destacarem os artefatos de segurança propiciados pela profissionalização da prática como recursos para 0 abrandamento dos perigos:

Hoje em dia, nas competições oficiais, é exigido capacete. Desde quando surgiu essa onda de usar capacete, tudo vai da melhoria, digamos assim, dessa visão de se proteger. Eu já uso há no mínimo oito anos, já fui protegido por ele e também uso cotoveleira (Vaqueiro Santa Terezinha 49).

Voltamos a considerar que esse cenário da mediação dos riscos existe dentro de um contexto mais amplo de disseminação de técnicas e conhecimentos em torno da corporeidade, o que tem grande ressonância nas atitudes elaboradas pelos vaqueiros para prevenir as ameaças ou, ao menos, amenizar os seus efeitos. Dessa maneira, a submissão aos perigos se configura como um ritual pelo qual eles conciliam saberes adquiridos a partir de diferentes áreas do conhecimento:

Eu particularmente me preparo, faço atividade física, faço academia, musculação (Vaqueiro Brejo Santo 33).

Tem que correr bem, tem que ter preparo físico pra saber se proteger na hora da queda (Vaqueiro Petrolina 43).

A gente precisa alongar para não haver distensão, fazer um alongamento básico e, quando tem um tempinho, [a gente vai] para a academia para endurecer as carnes, porque senão não aguenta (Vaqueiro Flores 38).

A partir dessas considerações, identificamos a percepção do conhecimento como ferramenta indispensável a ser buscada pelos desportistas. Atualizar-se quanto aos procedimentos e técnicas no intuito de proteger a si mesmo e o animal e, ao mesmo tempo, melhorar sua performance, torna-se um exercício fundamental. Ao que parece, percebem aí um processo de atualização que lhes permite acompanhar a evolução da vaquejada. Nisso 
verificamos, ainda, os reflexos de um processo mais geral marcado pela valorização do conhecimento perito, algo também pontuado por Giddens (1991), ao identificar os modos como o ambiente social passou a ser marcantemente organizado por sistemas de excelência técnica ou competência profissional, bem como em abordagens em que se reconhece uma dinâmica pela qual,

[...] o corpo, assim como o self, torna-se um local de apropriação, interação e reapropriação, ligando processos reflexivamente organizados e conhecimento perito sistematicamente ordenado (WILLIAMS; BENDELOW, 1998, p.68).

É precisamente a partir da adoção de medidas de planejamento condizentes com as regras atuais da vaquejada que os participantes se sentem minimamente seguros para experenciar o prazer propiciado pela vaquejada. Ou seja, tem-se um esforço de vivenciar uma emoção - a sensação da adrenalina - que é gestada em meio aos riscos existentes e que, de acordo com eles, "só a vaquejada é capaz de proporcionar". Vimos aí uma dinâmica que podemos pensar mais uma vez a partir da lógica da busca pela excitação, racionalmente orientada, tal como detalhada por Elias e Dunning (1992). E, nesse mesmo sentido, ao percebermos que códigos afetivos aparecem como elemento mobilizador dos esforços individuais de adequação às novas regras da vaquejada, enxergamos a "capacidade micropolítica das emoções" reconhecida por Rezende e Coelho (2010), ou seja, "seu potencial para dramatizar/alterar/ reforçar a dimensão macrossocial em que as emoções são suscitadas e vivenciadas".

Vale ressaltar que também a lesão aparece como uma experiência física que, no entanto, não pode ser reduzida a tal dimensão, visto que sua ocorrência nos fala, ainda, de uma dimensão simbólica, assim como dos valores e significados atribuídos por quem a experiencia. Há, portanto, um fundo antropológico pelo qual se permite entender seu acontecimento e os seus efeitos. Nos casos que analisamos, o risco da lesão reivindica igualmente um mecanismo de responsabilização por parte dos praticantes, o que também é evidenciado em outras histórias:

A vaquejada é um esporte, e se você não estiver preparado para ela, vai haver algum problema sim. Veja só... ano passado eu passei uns seis meses afastado das competições por uma lesão no ombro que eu acredito que aconteceu porque eu não aqueci. [...] E eu vinha muito sedentário em minha vida. Um médico queria até operar, eu disse que não faria a cirurgia. E então depois disso, eu fiz um tratamento com fisioterapia, e o médico também [me recomendou] fazer musculação, e eu vi o quanto foi importante, e o quanto esse cuidado mudou nas reações do meu corpo. Antes eu ficava muito dolorido depois de uma corrida de vaquejada, mas agora não. Depois que eu comecei a me dedicar a fazer uma atividade física regular, manter o corpo em exercício, isso mudou bastante (Vaqueiro Bezerros 35).

Suas percepções acerca dos riscos a que se encontram submetidos também ilustram seu olhar quanto à necessidade de mudanças comportamentais, no que se enfatiza, mais uma vez, o peso da responsabilidade individual. Não foi rara a sua ênfase nas atitudes de sensatez esperadas pelo vaqueiro profissional, ao passo em que renegaram hábitos que, segundo eles, marcaram a atividade em suas fases mais antigas, devendo, portanto, serem abandonados. Um exemplo disso diz respeito ao consumo de bebidas alcoólicas. Tanto nas conversas informais quanto ao longo das entrevistas, os vaqueiros fizeram menção ao fato de que, antigamente, 0 ato de participar dos eventos sob o efeito do álcool não se constituía como um problema e, ao contrário, era bastante comum. Hoje, no entanto, entendem que os próprios atletas devem responsabilizar-se em relação aos perigos envolvidos nessa prática, já que ainda não há uma fiscalização severa por parte dos organizadores quanto a isso. 
Hoje em dia ele [o vaqueiro] tem que não beber, pra ter consciência do que tá fazendo. Ele tem que primar pelo preparo físico. [...] Então tudo isso tem que ter regras, coisa que antes não tinha; era uma prática cultural que a gente fazia de todo jeito e estava ótimo (Vaqueiro Petrolina 43).

Ainda quanto ao consumo de álcool, o mesmo entrevistado nos sugere, para além da preocupação com a integridade física, uma moralidade pela qual procura desvencilhar a figura do vaqueiro de um imaginário marcado por excessos:

\begin{abstract}
Tem muito tempo que eu e muitos outros lutam para que a vaquejada perca um pouco da mística que tinha antes, [de que era] apenas [...] para se divertir, onde os vaqueiros iam só para tomar cachaça. E hoje, depois que tem se profissionalizado, ela é mais séria. Os vaqueiros iam só para tomar cachaça, ia namorar e [essa referência] ficou muito impregnada na cabeça das pessoas. Que era só essa diversão, farra, entendeu? [...] Nos torneios [...] lá pro lado do interior de São Paulo, vai muita família, corre mulher, menino... [...] E isso é bom, porque desmitifica isso que a vaquejada é só farra e bebedeira. Porque não é. Hoje em dia não é mais assim, mas ainda é descriminado. Mas a gente tá mudando isso já (Vaqueiro Petrolina 43).
\end{abstract}

Logo, conforme sugerem os entrevistados, as dinâmicas atuais da vaquejada, fundamentalmente perpassadas por regramentos a serem assimilados e reproduzidos pelos praticantes, dispõem entre os vaqueiros a incumbência de orientar seu comportamento e construir suas performances. $E$, também de acordo com algumas narrativas, o processo de espetacularização que marca a vaquejada nos dias de hoje, ao promover a maior visibilidade do atleta, Ihe exige igualmente um maior cuidado com seus hábitos cotidianos, bem como em relação à apresentação em si. Importante notar que, nesses casos, os modelos de comportamento não são necessariamente impostos por instâncias tradicionais, como 0 Estado ou religião por exemplo: ao invés disso, nos falam de modos de readaptação que os próprios sujeitos tomam como questão moral. Assim, a partir da nova percepção do risco que foi propiciada pelo processo de profissionalização da vaquejada, também se configuram dinâmicas de recriação de si. É nesse sentido que se vislumbram processos subjetivos a partir dos agenciamentos e conexões que esses indivíduos estabelecem em seu cotidiano. É a partir da ligação desses sujeitos com as novas práticas e sentidos orientadores da vaquejada - em que a noção de risco adquire um lugar fundamental - que se processa a reinvenção de si a que estamos nos referindo. Ou, dito de outro modo, a maneira de enxergar essas ameaças nos fala diretamente das formas de assimilação, apropriação e reação por parte dos entrevistados, se constituindo como elemento fundamental da sua identificação como vaqueiro. Vemos, então, sujeitos dispostos a se refazerem e a revisarem seus próprios hábitos de modo a distanciarse daquilo que entendem como atributos negativos tradicionalmente associados à figura do vaqueiro e à vaquejada.

Ainda no que concerne à racionalização dos riscos, entendemos que, por mais que reconhecessem o valor do esforço pessoal para prevê-los e administrá-los, os participantes muitas vezes assumiam a impossibilidade de seu controle absoluto. Haveria, portanto, nesses riscos, uma dimensão que lhes escapava, no que a fé em Deus se configurava como meio de enfrentá-lo. Logo, mesmo aqueles que não se identificavam como religiosos, ao falarem de seus rituais de preparação, aliavam os aspectos racionais à sua crença: hora, porque não é brincadeira não, é coisa séria (Vaqueiro Santa Terezinha 49). 
Sempre [fazer] a oração e atividade física. Deveria fazer sempre, só que nem todos fazem (Vaqueiro Exu 38).

Sempre faço uma oração antes de entrar na pista e depois de sair da competição, pedindo para que ele me proteja e me livre de qualquer acidente. Se eu for merecedor de ganhar qualquer prêmio, isso vai ser só um detalhe. 0 mais importante é minha integridade física e do meu companheiro que tá ali comigo batendo esteira, e também dos animais, que estão ali na competição para que ninguém se machuque. É isso aí que eu peço (Vaqueiro Bezerros 35).

Vemos, portanto, mais uma vez, a mobilização de elementos que, sob a perspectiva da razão instrumental que define e orienta a gestão dos riscos, seriam associados à irracionalidade, mas que adquirem um lugar significativo nas estratégias elaboradas pelos indivíduos na gestão de seu cotidiano. A eles se reserva um sentido e uma intencionalidade importantes para a dinâmica de construção e atuação do ser vaqueiro. Quanto a isso, é importante relembrarmos algo já descrito a respeito da presença marcante de símbolos e referências religiosas nos lugares em que ocorrem os eventos.

Foi também pela sua interpretação dos riscos a que são expostos, e por meio da descrição dos sentidos que eles ocupam nos seus empreendimentos de si, que identificamos algumas de suas percepções acerca das diferenças de gênero. Nesse sentido, a exposição ao perigo se revela como importante dado em se tratando de sua compreensão dos lugares e papeis atribuídos aos homens e às mulheres. Por conseguinte, o desenvolvimento deste tema também evidenciou a sua visão acerca da atuação feminina na vaquejada, encarada de formas distintas pelos entrevistados:

Eu acho o esporte meio violento. A mulher é mais sensível, foi criada para ser sensível. 0 esporte da vaquejada é um esporte de muitos riscos, que não tem essa sensibilidade. [...] Ela tem que ser inteligente ao ponto de saber que é um esporte de risco, é um esporte grosso que mexe com o bruto. Mas se a mulher acha que deve participar, é treinar se pegar com Deus e vir para vaquejada (Vaqueiro Santa Terezinha, 49).

Eu acho que é um esporte muito agressivo e que exige muita força, e acho que a mulher não devia competir, certo? Não é machismo, não é ignorância, mas eu não vejo a vaquejada como um esporte feminino. Eu respeito e admiro muito as mulheres que participam, mas eu acho que não é um esporte feminino (Vaqueiro Bezerros 35).

Vê-se então que, embora reconheçam que a modernização da prática trouxe novas possibilidades de racionalizar os riscos e controlar suas próprias performances, esse exercício não estaria plenamente disponível às mulheres justamente por sua "natureza sensível". Os gestos e atitudes exigidos a partir da presença dos riscos são aqui apresentados para embasar suas diferentes opiniões quanto à admissão e permanência de homens e mulheres na vaquejada.

Cabe ressaltar que a tendência a se justificar o talento e a potencialidade para as práticas esportivas a partir de uma visão natural das diferenças de gênero se constitui como um traço marcante da nossa trajetória enquanto sociedade, conforme sugerido por Goellner (2007). Os distintos lugares reservados a homens e mulheres a partir da influência de uma dicotomia inaugurada na modernidade, pelo que se associaram aos primeiros os atributos mentais, e, portanto, ao uso da razão, também serviram para justificar a inabilidade feminina para determinadas práticas corporais, reforçando seu vínculo à dimensão afetiva e à esfera 
doméstica: "a eles a aventura, a potência, o desafio, a força; a elas, a aventura comedida, a potência controlada, a força mensurada, o desafio ameno", sem que comprometa sua "graciosidade, a delicadeza e a beleza" (GOELLNER, 2007 p.185). Vemos, então, que essas referências de feminilidade aparecem de forma marcante nos dois últimos depoimentos.

Embora o primeiro entrevistado reconheça a influência da "criação", ou seja, das construções de gênero que nos são impostas pelos processos de socialização, o argumento recai naquilo que seria a condição inata da mulher, pelo que seus processos de administração dos perigos se revelariam precários. Há, portanto, uma percepção dos riscos orientada por padrões hegemônicos de masculinidade e feminilidade.

Por outro lado, as referências trazidas pelos depoimentos acima nos sugerem a reprodução, ainda que parcial, dos atributos de masculinidade que compõem a produção da figura do homem nordestino tal como apresentada por Albuquerque Júnior (2003), referência teórica já apresentada por nós. Percebe-se, então, que a noção de risco expressa por esses entrevistados parece assegurar a manutenção de algumas características tradicionalmente atreladas ao homem nordestino, e, no seu caso mais específico, à imagem do vaqueiro. Vislumbramos, assim, uma ambiguidade fundamental: um processo transitório da construção de si como forma de adequar-se às novas formas da vaquejada que, no entanto, coexiste com a manutenção de antigos traços identitários pautados numa perspectiva essencialista das diferenças entre homens e mulheres.

Assim, os modos de percepção dos riscos, tal como impulsionada pelo processo de esportivização da vaquejada, revelam a coexistência de referências tradicionais e ressignificações do ser vaqueiro. É pela sua compreensão dos perigos que historicamente têm sido associados a essa atividade que vemos a medida de seu envolvimento com um projeto de preservação de elementos tradicionais, mas também com uma dinâmica de adaptação às mudanças entendidas como necessárias para a manutenção da vaquejada.

\section{CONSIDERAÇÕES FINAIS}

Por um lado, este estudo permitiu-nos compreender a percepção do risco enquanto uma construção social e também como uma dinâmica subjetivamente trabalhada. Longe de se pretender excluído de sua rotina, os sujeitos o identificam por meio de uma moralidade afetiva, reconhecendo sua utilidade nas sensações de prazer que Ihes propiciam, ao mesmo tempo em que o inclui como elemento central em seus projetos de racionalização. Sabe-se que o próprio campo da Educação Física emergiu a partir de uma relação com a dimensão afetiva, pelo que foi pensada como objeto a ser racionalmente controlado. Nesse mesmo contexto, a afetividade foi colocada como a marca da inaptidão às práticas esportivas, essas que, por sua vez, enquanto produto da modernidade, preconizavam o uso da razão e do controle de si. Portanto, este estudo nos coloca a possibilidade de repensar os lugares ocupados pelas gramáticas afetivas nos processos de racionalização subjacentes às nossas práticas corporais, entendendo-as como processos sujeitos a atualizações, tal como é possível perceber por meio das dinâmicas dos vaqueiros entrevistados. Nesses casos em específico, eles próprios reconhecem suas emoções como mobilizadoras dos empreendimentos de si. Foi por esse caminho que pudemos identificar as intencionalidades que surgem a partir dos sentimentos despertados pelos perigos, pelo quais organizam o cultivo de seus corpos e de seus comportamentos afetivos como forma de manejá-los. 
Entendemos que os sentidos das experiências do risco não podem ser entendidos sem considerarmos os aspectos culturais e morais envolvidos nas trajetórias de seus praticantes, evidenciados nas trajetórias aqui descritas. Por conseguinte, eles também nos ajudaram a identificar as motivações e os significados da busca por determinadas práticas esportivas, bem como temáticas caras à Educação Física e aos estudos das práticas corporais: história, memória, relações de gênero, configurações políticas e aspectos civilizatórios que atravessam as construções do corpo e das subjetividades.

Reconhecemos que a relação com o risco não está isolada da configuração social geral em que os perigos que atravessam nossos corpos tornaram-se 0 alvo principal de nossos processos de conscientização e reflexividade, levando-nos a combatê-los em meio ao conhecimento perito disponibilizado por agentes diversos. No caso dos entrevistados, contudo, as ameaças aparecem de forma ambivalente nas suas negociações diárias: tanto simbolizam aquilo que pode danificar o corpo como se configuram como elemento pelo qual o sujeito pode ter sua capacidade e desempenho enaltecidos. A esse respeito, cabe lembrar que diversos vaqueiros falaram de seu retorno à vaquejada mesmo após algum acidente sofrido durante as competições. Nesse caso, seu contato com os riscos assume lógicas, racionalidades e sensibilidades próprias e, portanto, tomam parte nos significados que atribuem às suas próprias práticas corporais e subjetivas, especificidades fundamentais na compreensão das dinâmicas esportivas. Esperamos contribuir com análises em torno das práticas corporais que levem em conta enunciados como esses, cujas intencionalidades são muitas vezes negligenciadas.

\section{REFERÊNCIAS}

ALBUQUERQUE JÚNIOR, Durval Muniz. Nordestino: uma invenção do falo; uma história do gênero masculino (Nordeste - 1920/1940). Maceió: Catavento, 2003.

ASSOCIAÇÃO BRASILEIRA DE VAQUEJADA (ABVAQ). Disponível em <http://www.abvaq.com. brl>. Acesso em: 2 set. 2018.

BECK, Ulrich. The risk society: Towards a new modernity. Londres: Sage, 1992.

ELIAS, Norbert; DUNNING, Eric. A busca da excitação. Lisboa: Memória e Sociedade, 1992.

GEERTZ, Clifford. Uma Descrição Densa: Por Uma Teoria Interpretativa da cultura. In: GEERTZ, Clifford. A Interpretação das culturas. Rio de Janeiro: Zahar, 2008. p.13-41.

GIDDENS, Anthony. As conseqüências da modernidade. São Paulo: UNESP, 1991.

GOELLNER, Silvana. Feminismos, mulheres e esportes: questões epistemológicas sobre 0 fazer historiográfico. Movimento, v.13, n.2, p.176-196, maio/ago. 2007.

MÉLO, Roberta de Sousa. Da visibilidade dos corpos disformes: um estudo sobre cirurgias cosméticas mal sucedidas. 2012. 207 f. Tese (Doutorado), Programa de Pós Graduação em Sociologia, Universidade Federal de Pernambuco, Recife, 2012.

MOURA, Diego Luz; FERREIRA, Marcos Santos; SOARES, Antonio Jorge Gonçalves. Compreender, relativizar e desconstruir: Os discursos do risco na produção acadêmica sobre esportes de aventura. Licere, v. 19, n. 1, p.1-20, 2016. 
REZENDE, Claudia Barcellos; COELHO, Maria Claudia. Antropologia das emoções. Rio de Janeiro: Editora FGV, 2010.

SOUSA, Gudson Gleyton Queirós de; BROLLO, Carlos Henrique Jasmim. Prevalência de lesões ortopédicas em atletas de vaquejada. Revista Brasileira de Ciências do Esporte, v. 33, n. 1, p. 207-217, 2011.

WILLIAMS, Simon J.; BENDELOW, Gillian A. The Lived Body: Sociological Themes, Embodied Issues. London: Routledge, 1999. 